\title{
Serum antibody response to Staphylococcus aureus enterotoxins and TSST-1 in patients with septicaemia
}

\author{
K. KANCLERSKI, B. SÖDERQUIST*, M. KJELLGREN†, H. HOLMBERG* and R. MÖLLBY \\ Microbiology and Tumorbiology Center, Karolinska Institutet, Stockholm, ${ }^{*}$ Department of Infectious Diseases, \\ Örebro Medical Center Hospital, Örebro and †Department of Bacteriology, Swedish Institute for Infectious \\ Disease Control, Stockholm, Sweden
}

\begin{abstract}
The prevalence of enterotoxins and toxic shock syndrome toxin (TSST-1) production in strains isolated from patients with Staphylococcus aureus septicaemia, and the serum antibody response in relation to toxin production in vitro of each isolate, were investigated. Among 63 strains of $S$. aureus isolated from the blood of patients with septicaemia, 51 from patients with superficial wounds and 49 from nasal carriers, 50$60 \%$ produced at least one of the enterotoxins A-D or TSST-1. The most frequent toxins produced were enterotoxins $A$ and $C$ and TSST-1. Among the 63 patients with staphylococcal septicaemia, $51(81 \%)$ had a significant rise or a high antibody titre, or both, to at least one of the toxins. A positive serological response to toxin $A$ was found in $78 \%$, to enterotoxin $B$ in $83 \%$, to enterotoxin $C$ in $80 \%$, to enterotoxin $D$ in $86 \%$ and to TSST-1 in $92 \%$ of the patients from whom the isolated strain produced the respective toxin. Antibodies against enterotoxins A, B, C and D and TSST-1 were also seen in 35\%, $16 \%, 32 \%, 59 \%$ and $10 \%$, respectively, in patients infected by strains that did not produce the specific toxin. Immunological cross-reactions between the toxins were demonstrated both in hyperimmune sera obtained from rabbits and in patients' sera, particularly between enterotoxins $B$ and $C$. It is concluded that these potent toxins with superantigenic properties are produced in vivo during $S$. aureus septicaemia. No differences with regard to enterotoxin or TSST-1 production or antibody response were noted between patients with complicated versus uncomplicated septicaemia.
\end{abstract}

\section{Introduction}

Staphylococcus aureus is the cause of a wide spectrum of human infections ranging from the common boil to osteomyelitis, toxic shock syndrome and septicaemia. The latter is a serious disease with a mortality of 20 $30 \%$ [1] and an increasing prevalence [2]. The ability of $S$. aureus to cause such a wide range of diseases may be associated with its production of a large number of extracellular toxins and other virulence factors. It is known that some of them are important in specific diseases such as toxic shock syndrome, scalded skin syndrome and food poisoning. The exact roles of the individual extracellular products in the pathogenesis of a systemic infection such as septicaemia are still not clear.

The staphylococcal enterotoxins are a group of closely related protein toxins that cause gastrointestinal

Received 23 May 1995; accepted 31 July 1995. intoxication [3]. Toxic shock syndrome toxin (TSST1) is the significant toxin in the pathogenesis of toxic shock syndrome (TSS) $[4,5]$. These toxins have other biological activities such as pyrogenicity and T-cell mitogenicity. They are potent inducers of various cytokines, such as interferons, interleukins and tumour necrosis factor [6-11]. The toxins also display superantigenic properties, i.e., they bind directly to class II major histocompatibility complex (MHC) proteins and, as such complexes, stimulate $T$ cells carrying particular $\mathrm{V}$ beta variants. These superantigens act at nanomolar concentrations and do not require the processing typical for normal antigens [12-16]. Thus, there are reasons to suggest that the enterotoxins and TSST-1 can play an important role in diseases other than food poisoning and TSS.

The capability of $S$. aureus strains isolated from different sources to produce enterotoxins and TSST-1 and the antibody response against them have been studied previously. The published data differ widely and depend on the country where the study was performed as well as on the methods used. For 
instance, production of TSST- 1 was found in only $5 \%$ of isolates in Hungary [17], in $20 \%$ in Switzerland [18] and in as many as $52 \%$ among isolates from different regions of the USSR [19].

The aim of this study was to investigate the prevalence of enterotoxin and TSST-1 production in vitro by strains isolated from patients with $S$. aureus septicaemia and from carriers and to confirm their production in vivo through determination of serum antibody responses to them in septicaemic patients.

\section{Materials and methods}

\section{Patients}

Production of enterotoxins A, B, $\mathrm{C}_{1}$ and D and TSST-1 was determined in 63 strains isolated from the blood of septicaemic patients, 49 strains isolated from the nasopharynx of healthy carriers and 51 strains isolated from superficial wounds of out-patients.

IgG antibodies against staphylococcal enterotoxins A, $\mathrm{B}, \mathrm{C} 1$ and D and TSST- 1 were determined in 166 sera from 63 patients, aged 10-91 years (median 70), with $S$. aureus septicaemia verified by positive blood culture. The serum samples were drawn on admission and subsequently about once a week. Sera were stored at $-70^{\circ} \mathrm{C}$ until assayed. The patients had been admitted to the Department of Infectious Diseases of the Örebro Medical Center between 1988 and 1992 with clinical signs of septicaemia, such as fever $>38.5^{\circ} \mathrm{C}$, shaking chills, tachypnoea, tachycardia and hypotension. Forty-seven patients had communityacquired septicaemia and in 16 cases the septicaemia was contracted during hospital stay. None of the patients presented the clinical signs and symptoms of toxic shock syndrome (TSS). Immunosuppression was found in seven patients and malignant disease was present in four; 13 patients had diabetes mellitus.

Complicated septicaemia, defined as a complicated clinical course with septic metastases, such as acute osteomyelitis, septic arthritis or extensive abscesses (long-standing, insufficiently drained), was found in 43 patients. Endocarditis, according to the strict case definition of von Reyn [20], was found in 15 patients. Five $(8 \%)$ of the patients died soon after the acute septicaemic event (3-15 days after admission to hospital). Uncomplicated septicaemia without any evident focus was present in 20 patients.

Acute and convalescent sera from 24 patients, 32-96 years old (median 74), with septicaemia due to aetiological agents other than $S$. aureus served as controls. The following bacteria were isolated from these patients: Streptococcus pneumoniae $(\mathrm{n}=9)$, Escherichia coli (6), S. epidermidis (2), Klebsiella pneumoniae (2), Str. pyogenes (1), Str. agalactiae (1),
K. oxytoca (1), Enterobacter cloacae (1) and Bacteroides fragilis (1).

To determine the upper limits of normal serum IgG titres to staphylococcal enterotoxins and TSST-1, sera from 103 healthy individuals were examined and assumed to represent a 'normal population', mainly blood donors 20-88 years old (median 45). As in a normal population, recent or current minor staphylococcal infections were not excluded.

\section{Production of enterotoxins $A, B, C$ and $D$ and TSST-1 by isolates of $S$. aureus}

Enterotoxin and TSST-1 production by $S$. aureus strains isolated from patients were tested by reversed passive latex agglutination (RPLA) with commercial kits SETRPLA and TST-RPLA (Oxoid, Unipath Ltd) according to the manufacturer's instructions. The strains were cultivated for $20 \mathrm{~h}$ in brain heart infusion broth at $37^{\circ} \mathrm{C}$ and the supernates were diluted from 1 in 2 to 1 in 128 (two-step dilution) in a 96-well microtitration plate. Latex suspensions, sensitised with specific antibodies, were added to each dilution. The agglutination was read after incubation overnight at room temperature.

\section{ELISA}

Immulon-2 polystyrene 96-well microtitration plates (Dynatech Lab, Virginia, USA) were coated with PBS solutions of enterotoxins $\mathrm{A}, \mathrm{B}, \mathrm{C}$ or D or TSST-1 (Toxin Technology Inc, FL, USA) overnight at room temperature. The optimal coating doses were determined by antigen titration and were $0.5 \mu \mathrm{g} / \mathrm{ml}$ for enterotoxins A, C and D and TSST- 1 , and $0.25 \mu \mathrm{g} / \mathrm{ml}$ for enterotoxin B. Plates were washed four times with PBS supplemented with Tween 20 (PBS-T) and dilutions of sera were added. The following dilutions of sera were used: 1 in 1000 for determination of antiSEA and anti-SED titre, 1 in 2000 for anti-SEB and anti-TSS titre, 1 in 4000 for anti-SEC titre. The plates were incubated for $1 \mathrm{~h}$ at room temperature and then washed three times with PBS-T. Anti-human IgG conjugates (Sigma) were added and plates were incubated at room temperature overnight. The ELISA was developed with $p$-nitrophenyl phosphate as substrate (Sigma); a volume of $100 \mu \mathrm{l}$ was used in each step. The test results including developing time were continuously standardised against five human reference sera with known titres.

The ELISA titre was defined as the absorption value at $405 \mathrm{~nm}$ multiplied by the serum dilution. A high titre was defined as a value higher than the upper limit of the sera from the normal population. A significant rise of titre was defined as at least a twofold increase between the acute and a later sera. A patient with a high titre or a significant rise of titre, or both, was considered to have positive serology. 


\section{Immunological cross-reactions}

Immunological cross-reactions between enterotoxins $\mathrm{A}$, B, C and D and TSST-1 were studied with rabbit sera. For each toxin two rabbits were immunised five times intramuscularly at 2-week intervals. Rabbits were bled 2 weeks after the last immunisation and the sera were analysed by ELISA according to the above procedures with anti-rabbit IgG conjugate (Sigma).

\section{Statistical methods}

Fisher's exact test was used for two-sided comparisons between groups.

\section{Results}

\section{Toxin production}

Thirty-seven strains (59\%) of $S$. aureus isolated from the 63 patients with septicaemia produced at least one of the enterotoxins or TSST-1, or both (Fig. 1). The

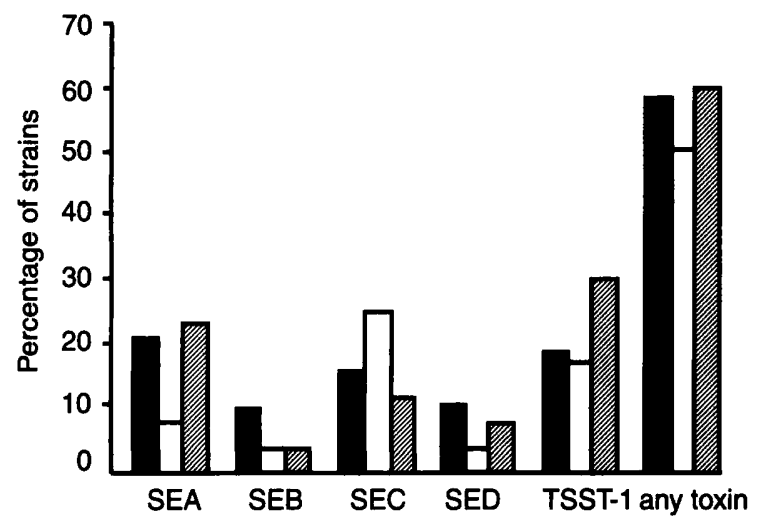

Fig. 1. Production of enterotoxins A-D and TSST-1 by strains isolated from 63 patients with $S$. aureus septicaemia $(\square), 51$ out-patients with superficial wounds $(\square)$ and 49 nasal carriers $(\square)$. most frequent were enterotoxin $\mathrm{A}$, enterotoxin $\mathrm{C}$ and TSST-1 which were found in $14(22 \%), 10(16 \%)$ and $12(19 \%)$ strains tested, respectively. Enterotoxin B was produced by only $6(10 \%)$ and D by $7(11 \%)$ strains. Twelve strains produced more than one toxin. The most common combination was enterotoxin A and TSST-1, which was found in $8(13 \%)$ strains.

Distribution of toxin production by strains isolated from nasal carriers and from superficial wounds exhibited a similar profile to those isolated from septicaemic patients but with some divergences (Fig. 1).

\section{Antibody response}

The presence of IgG antibodies against staphylococcal enterotoxins and TSST-1 was studied in 103 healthy individuals. No distinct age-correlated variations were found in any age group for all tested toxins (data not shown). Therefore, the common upper limit of normal titre values, set at the 95th percentile of the healthy controls, were 380 for anti-SEA and anti-SED, 1100 for anti-SEB, 2600 for anti-SEC and 1300 for anti-TSST-1 (Fig. 2).

Among 63 patients with staphylococcal septicaemia 51 $(81 \%)$ had a significant rise or high titre, or both, to at least one of the tested toxins. Positive serology, i.e., a high or a significant rise of titre, or both, to toxin A was found in $11(79 \%)$ of 14 patients from whom the strains producing enterotoxin A were isolated (Table 1). Corresponding figures for anti-enterotoxin B were 5 of 6 , for anti-enterotoxin C 8 of 10 , and for anti-enterotoxin D 6 of 7 patients infected by a strain producing the specific toxin (Table 1). Similarly, 11 (92\%) of 12 patients infected by strains producing TSST-1 showed a high titre or a rise in anti-TSST-1 titre, or both (Table 1). In eight cases, the strains

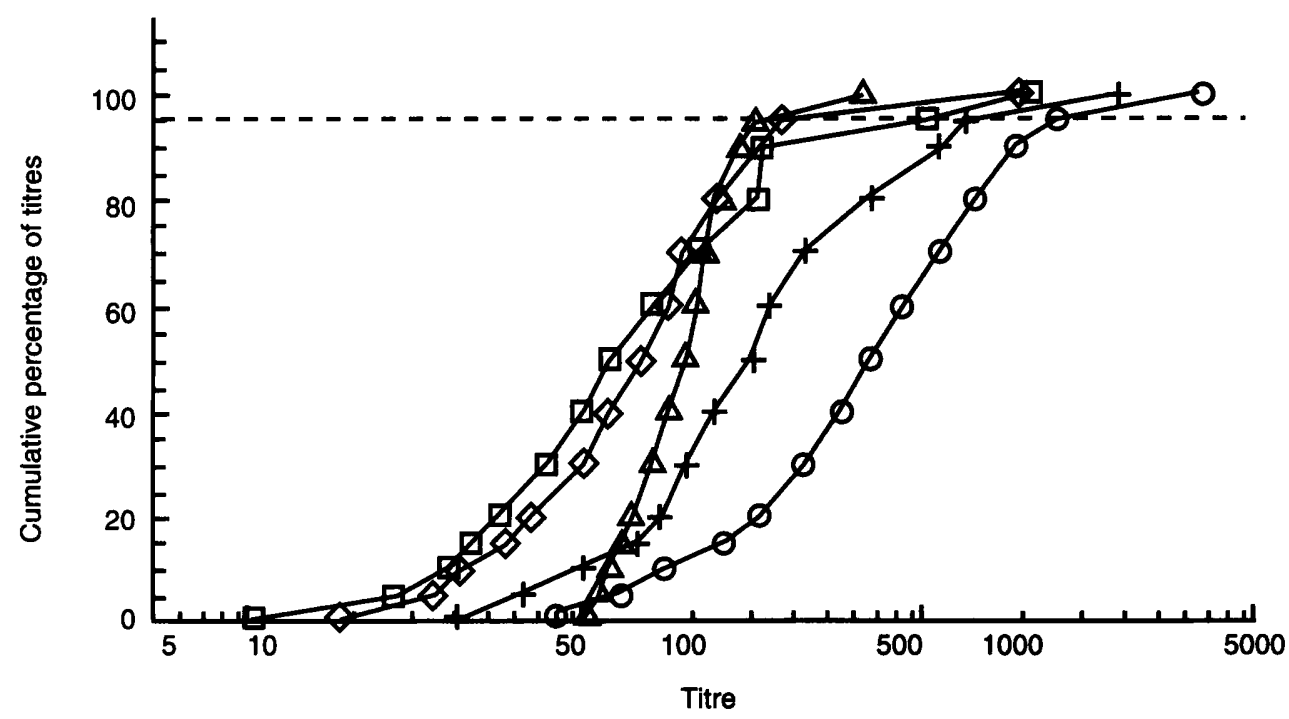

Fig. 2. Cumulative percentage of serum antibody titres against enterotoxin A $(\diamond), \mathrm{B}(\square), \mathrm{C}(\mathrm{O}), \mathrm{D}(\Delta)$ and TSST-1 (+) in 103 healthy controls. 
Table 1. Antibody response to staphylococcal enterotoxins and TSST-1 in patients with $S$. aureus and non-S. aureus septicaemia

\begin{tabular}{|c|c|c|c|c|c|}
\hline \multirow[b]{2}{*}{$\begin{array}{l}\text { Antibodies } \\
\text { against }\end{array}$} & & \multicolumn{3}{|c|}{ S. aureus septicaemia } & \multirow[b]{2}{*}{$\begin{array}{l}\text { Non-S. aureus } \\
\text { septicaemia }\end{array}$} \\
\hline & & $\begin{array}{l}\text { Isolate } \\
\text { produced } \\
\text { appropriate } \\
\text { toxin }\end{array}$ & $\begin{array}{c}\text { Isolate } \\
\text { produced } \\
\text { any but not } \\
\text { appropriate toxin }\end{array}$ & $\begin{array}{l}\text { Isolate } \\
\text { did not } \\
\text { produce } \\
\text { any toxin }\end{array}$ & \\
\hline \multirow[t]{5}{*}{ Enterotoxin A } & Number of patients & 14 & 23 & 26 & 24 \\
\hline & Number of patients (\%) positive by & & & & \\
\hline & rise in titre & $6(43)$ & $3(13)$ & $1 \quad(4)$ & $1(4)$ \\
\hline & high titre & $10(71)$ & $8(35)$ & $8(31)$ & $1(4)$ \\
\hline & rise and/or high titre & $11(79)$ & $9(39)$ & $8(31)$ & $2(8)$ \\
\hline \multirow[t]{5}{*}{ Enterotoxin B } & Number of patients & 6 & 31 & 26 & 24 \\
\hline & Number of patients (\%) positive by & & & & \\
\hline & rise in titre & $1(17)$ & $4(13)$ & 1 (4) & 0 \\
\hline & high titre & $5(83)$ & $6(19)$ & 1 (4) & $1(4)$ \\
\hline & rise and/or high titre & $5(83)$ & $8(26)$ & $2(8)$ & $1(4)$ \\
\hline \multirow[t]{5}{*}{ Enterotoxin $\mathrm{C}$} & Number of patients & 10 & 27 & 26 & 24 \\
\hline & Number of patients $(\%)$ positive by & & & & \\
\hline & rise in titre & $4(30)$ & $6(22)$ & $4(15)$ & 0 \\
\hline & high titre & $7(70)$ & $6(22)$ & $5(19)$ & 0 \\
\hline & rise and/or high titre & $8(80)$ & $9(33)$ & $8(31)$ & 0 \\
\hline \multirow[t]{5}{*}{ Enterotoxin D } & Number of patients & 7 & 30 & 26 & 24 \\
\hline & Number of patients $(\%)$ positive by & & & & \\
\hline & rise in titre & $3(43)$ & $8(27)$ & $4(15)$ & 0 \\
\hline & high titre & $6(68)$ & $17(57)$ & $14(54)$ & $1(4)$ \\
\hline & rise and/or high titre & $6(86)$ & $18(60)$ & $15(58)$ & $1(4)$ \\
\hline \multirow[t]{5}{*}{ TSST-1 } & Number of patients & 12 & 25 & 26 & 24 \\
\hline & Number of patients (\%) positive by & & & & \\
\hline & rise in titre & $5(42)$ & $3(12)$ & 0 & 0 \\
\hline & high titre & $11(92)$ & $3(12)$ & $3(12)$ & $1(4)$ \\
\hline & rise and/or high titre & $11(92)$ & $5(20)$ & $3(12)$ & $1(4)$ \\
\hline
\end{tabular}

produced both TSST-1 and enterotoxin A and a positive antibody response was found against both toxins in five patients. The kinetics of the respective antibody response are illustrated in Fig. 3, which shows the antibody response in each patient from whom the isolated strain produced the appropriate toxin and more than one serum sample was available. This figure demonstrates the relationship between high titre and the degree of rise in titre. The differences between the different toxins are also illustrated, as is the time of seroconversion.

Antibodies against enterotoxins A, B, C and D and TSST-1 also developed in patients infected by strains that did not produce the specific toxin or did not produce any toxin in vitro (Table 1). The summarised figures from columns 2 and 3 in Table 1, representing antibodies against toxins A, B, C and D and TSST-1, were $17(35 \%)$ of $49,10(18 \%)$ of $57,17(32 \%)$ of $53,33(59 \%)$ of 56 and $8(16 \%)$ of 51 , respectively. Among the patients with non- $S$. aureus septicaemia, a positive antibody response to enterotoxin $\mathrm{A}$ was found in $2(8 \%)$ of 24 , to enterotoxin B in $1(4 \%)$ of 24 , to enterotoxin $D$ in $1(4 \%)$ of 24 and to TSST- 1 in 1 $(4 \%)$ of 24 cases (Table 1 ).

Four $(40 \%)$ of 10 patients from whom strains producing toxin $\mathrm{C}$ were isolated also developed antibodies against toxin $\mathrm{B}$ and $5(83 \%)$ of 6 patients infected by strains producing toxin $B$ also developed antibodies against toxin C. Analogously, with immunised rabbits, enterotoxin $\mathrm{C}$ reacted identically with antisera raised against enterotoxin $B$ and antisera against enterotoxin $\mathrm{C}$, whereas enterotoxin $\mathrm{B}$ reacted with antisera against enterotoxin $\mathrm{C}$ only to a limited extent (Fig. 4b). Furthermore, minor cross-reactions between anti-toxin $\mathrm{A}$ and antigen $\mathrm{D}$ were noted (Fig. 4a). Hyperimmune sera from rabbits showed no cross-reactions between TSST-1 and the enterotoxins (data not shown).

No statistically significant differences in antibody response between patients with complicated and uncomplicated septicaemia were found. The same results were obtained in a comparison of endocarditis and non-endocarditis patients.

\section{Discussion}

Staphylococcal enterotoxins and TSST-1 exhibit diverse biological activities, but the pathogenic significance of these toxins is not fully understood. Therefore, it was of interest to investigate the capacity of $S$. aureus strains isolated from patients with septicaemia to produce enterotoxins $\mathrm{A}, \mathrm{B}, \mathrm{C}$ and $\mathrm{D}$ and TSST- 1 and the corresponding antibody responses to these toxins.

The present study analysed 63 isolates of $S$. aureus and 166 serum samples from 63 patients with staphylococcal septicaemia. The most frequent toxins produced by the strains were enterotoxins $\mathrm{A}$ and $\mathrm{C}$ and TSST- $1 ; 59 \%$ of isolates produced at least one of 


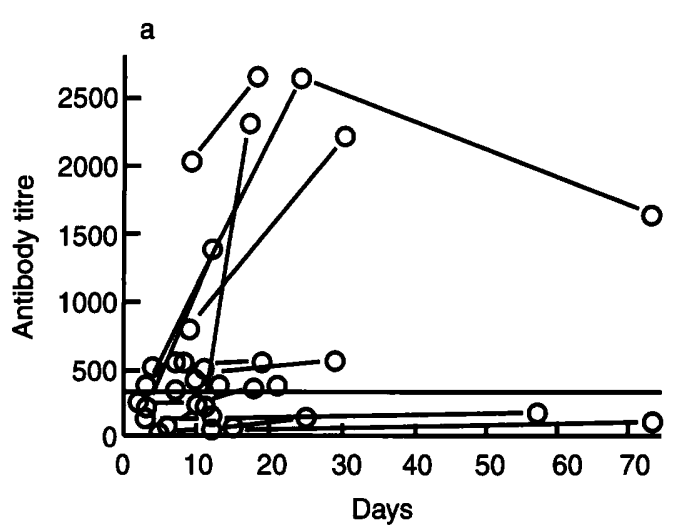

C

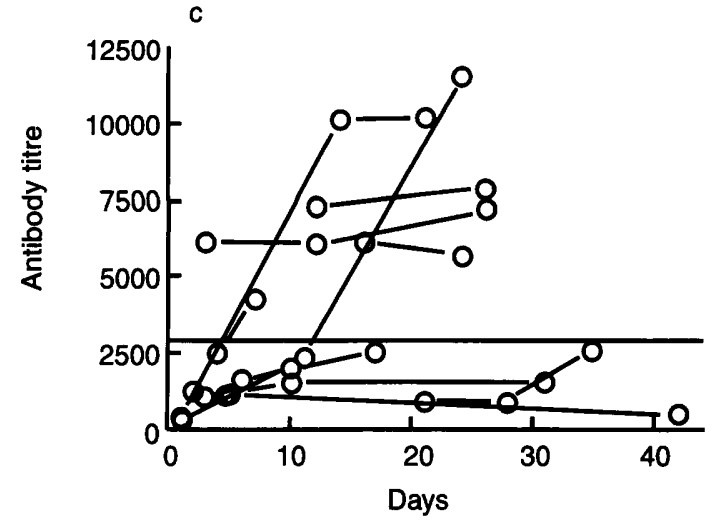

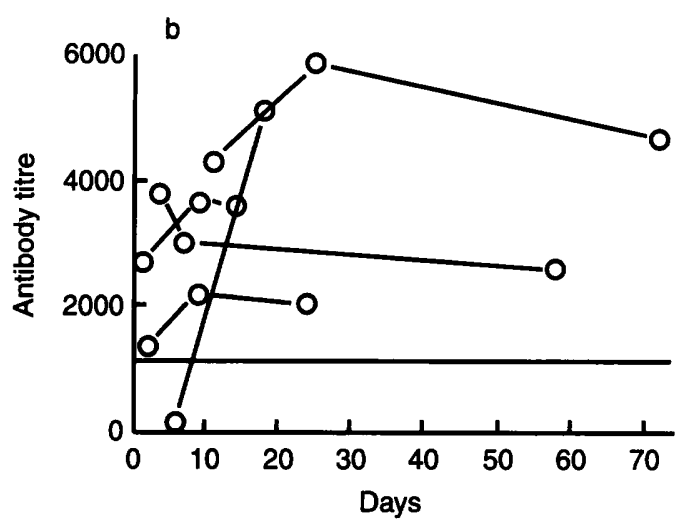

d

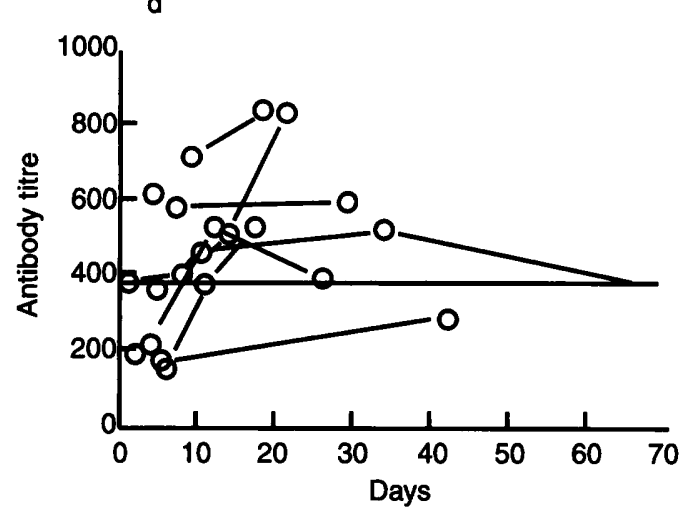

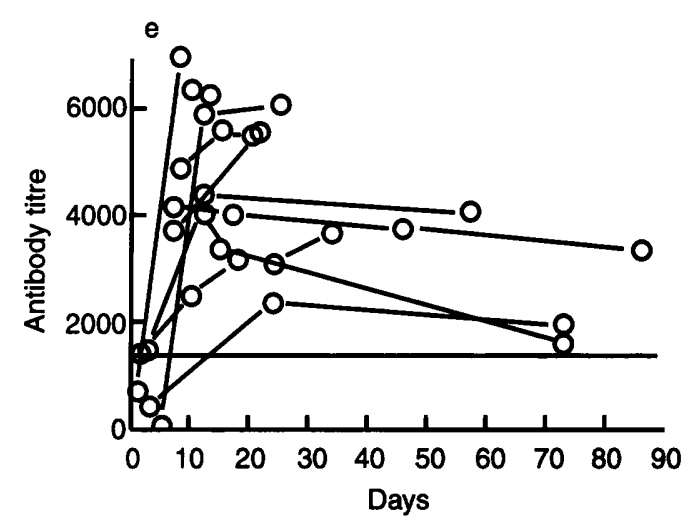

Fig. 3. Kinetics of antibody titres against enterotoxins A-D (a-d) and TSST-1 (e) in septicaemic patients infected by $S$. aureus strains that produced the appropriate toxin. Days indicate days after onset of disease.

the toxins. These data are different from those reported elsewhere. Among the $S$. aureus strains isolated in blood from Ireland [21], enterotoxins B, $\mathrm{C}$ and $\mathrm{D}$ were detected more often, whereas enterotoxin A was produced by similar and TSST-1 by lower percentages of strains as compared to the present study. On the other hand, enterotoxins A and B were detected more frequently and TSST-1 less frequently among clinical isolates in Germany [22]. In Sweden, the frequency of production of TSST-1 among $S$. aureus septicaemia strains was reported to be $18 \%$ [23] which is in agreement with our finding of $19 \%$.

No statistical difference in toxin production was found either among strains isolated from patients with endocarditis compared to those without endocarditis, or from patients with complicated septicaemia compared to uncomplicated septicaemia (data not shown).
Isolates from superficial wounds and carriers were investigated for production of enterotoxins and TSST1. Some differences in toxin production were noted among these groups (Fig. 1). Generally the toxins were produced by a lower percentage of strains isolated from wounds, but only in the case of enterotoxin A was the difference statistically significant. This result differs from those reported by Humphreys et al. [21], where isolates from carriers did not produce enterotoxins A, B or C and only a few of them produced enterotoxin D and TSST- 1 . The differences in toxin production reported by various authors could be due to different techniques used to detect them or to local geographical variations.

To set the upper limit of normal serum titres for antienterotoxins and anti-TSST-1, sera from 103 healthy controls were analysed. The lowest titre value was found for antibody to enterotoxin A. This is surprising 


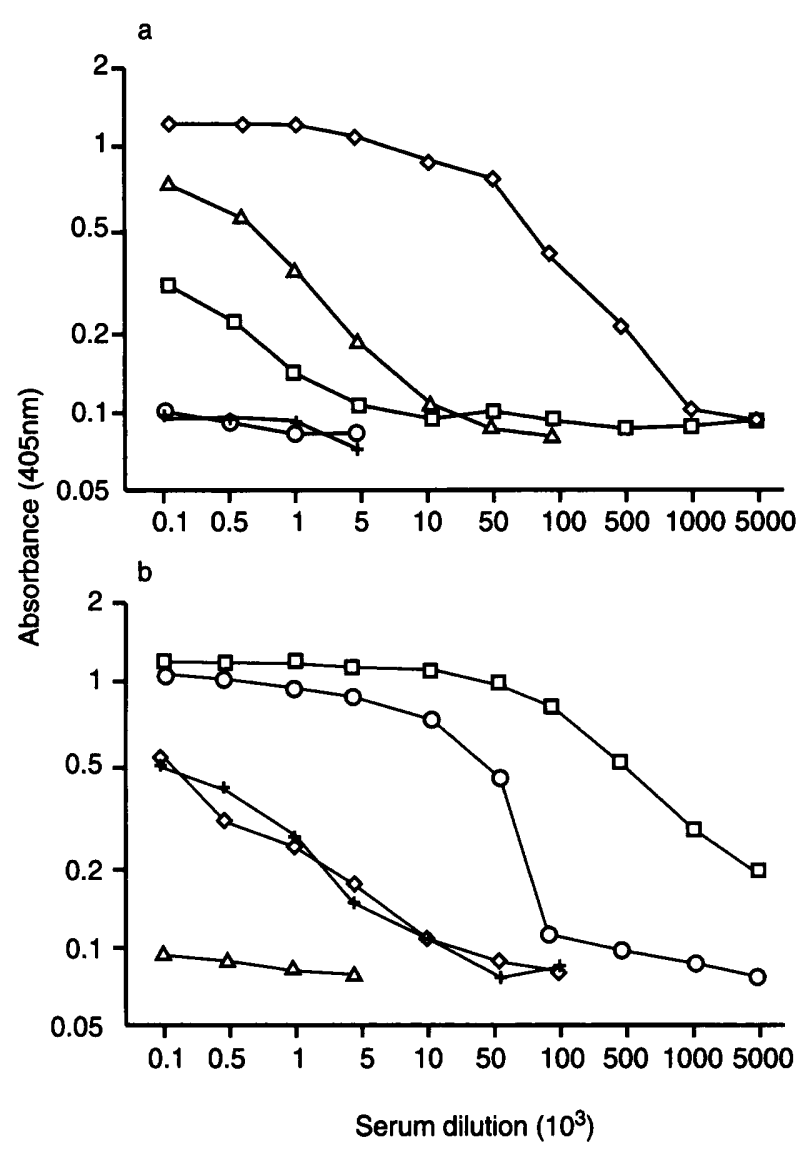

Fig. 4. Immunological reactions in ELISA of $\mathbf{A}$, enterotoxin A; B, enterotoxin B with hyperimmune sera obtained from rabbits immunised with enterotoxin $A$ $(\diamond), \mathrm{B}(\square), \mathrm{C}(\mathrm{O}), \mathrm{D}(\triangle)$ and TSST-1 $(+)$.

as this toxin is the most commonly produced enterotoxin in $S$. aureus strains. The absence of antibodies against enterotoxin $\mathrm{A}$ in about $50 \%$ of the population has also been reported in Germany [22]. The reason for this low frequency of serological response is not known, but enterotoxin A has been reported to cause inhibition in vitro of immunoglobulin production against other antigens by human B lymphocytes and not to cause production of specific Ig against itself in the presence of normal $T$ lymphocytes [24]. On the other hand, the latter study reports the same effects of TSST-1, while antibodies against this toxin are quite strongly produced by the population in general as well as by the septicaemic patients (Figs 2 and 3, Table 1). Furthermore, the patients infected with strains producing enterotoxin $\mathrm{A}$ also responded quite well.

A strong correlation was found between toxin production by the strains isolated from blood and the antibody response (Fig. 3, Table 1); 79-92\% of the patients developed antibodies against the toxin produced by the isolated strain. Positive serology as defined by high titre or significant rise of titres, or both, against the toxins which were not produced by isolated strains was also noted. However, this non- specific immune response was relatively weak, i.e., a barely significant rise of titre from low initial titres, sometimes without exceeding the upper limit value. Isolates from 26 patients did not produce any of the investigated toxins. Twenty-four of these patients could be fully analysed with respect to antibody response, but two of them were sampled $<7$ days after onset of disease. Sixteen $(67 \%)$ of these 24 patients displayed positive serology to at least one of the toxins. The majority of these only showed a high titre and not a rise in titre (Table 1). One patient gave a positive serological response to all toxins except enterotoxin $\mathrm{B}$, a finding that might be explained by oligoclonal or polyclonal stimulation. Among the non$S$. aureus septicaemia patients, a positive antibody response against the toxins was found in only a few cases (Table 1).

An unsolved question is whether this antibody response is non-specific or if appropriate toxin is not produced in vitro in detectable amounts. Another explanation could be immunological cross-reactions between the toxins $[25,26]$, which seems to be the case in some patients in this study, as similar responses to enterotoxin $\mathrm{C}$ in patients infected by strains producing enterotoxin $\mathrm{B}$ and vice versa were noted. This cross-reaction is explained by the common epitopes found for these toxins [26]. The non-specific reactions suspected in the human antisera were supported by the cross-reactions found with rabbit antisera (Fig. 4).

In all, $50-60 \%$ of strains isolated from patients with $S$. aureus septicaemia, wound infections or from carriers produced at least one enterotoxin or TSST-1, or both. A strong correlation between antibody response and production of the appropriate toxin was found in the septicaemic patients. Unexpectedly low titres of anti-enterotoxin A were found in healthy controls, whereas there was a significant antibody response to enterotoxin $\mathrm{A}$ in septicaemic patients. Immunological cross-reactions among the toxins were demonstrated both in hyperimmune sera obtained from rabbits and in patient sera, mainly between enterotoxins $B$ and $C$. No differences with respect to production of toxins or the antibody response were seen between patients with complicated and uncomplicated septicaemia.

Ms Patricia Colque-Navarro is acknowledged for an active interest in the work and Dr Lars Blad for providing some of the sera in the non$S$. aureus control group. This study was supported by the Wennergren Center Foundation, the Karolinska Institutet and the Research Foundation of the Department of Infectious Diseases, Örebro Medical Center Hospital.

\section{References}

1. Shah M, Watanakunakorn C. Changing patterns of Staphylococcus aureus bacteremia. Am J Med Sci 1979; 278: 115-121. 
2. Frimodt-Møller N, Espersen F, Rosdahl VT, Bentzon MW, Skinhøj P. Epidemiological aspects of Staphylococcus aureus bacteraemia in Denmark during 30 years from 1957-1987. In: Möllby R, Flock JI, Nord CE, Christensson B (eds) Staphylococci and staphylococcal infections. Stuttgart, Gustav Fischers Verlag. 1994: 9-11.

3. Tranter HS. Foodborne staphylococcal illness. Lancet 1990 ; 336: $1044-1046$.

4. Parsonnet J. Mediators in the pathogenesis of toxic shock syndrome: overview. Rev Infect Dis 1989; 11 Suppl 1: S263S269.

5. Todd J, Fishaut M. Toxic-shock syndrome associated with phage-group I Staphylococci. Lancet 1978; 2: 1116-1118.

6. Alber G, Hammer DK, Fleischer B. Relationship between enterotoxic- and $\mathrm{T}$ lymphocyte-stimulating activity of staphylococcal enterotoxin B. J Immunol 1990; 144: 4501-4506.

7. Andersson J, Nagy S, Björk L, Abrams J, Holm S, Andersson $\mathrm{U}$. Bacterial toxin-induced cytokine production studied at the single-cell level. Immunol Rev 1992; 127: 69-96.

8. Fischer $H$, Dohlsten $M$, Andersson $U$ et al. Production of TNF- $\alpha$ and TNF- $\beta$ by staphylococcal enterotoxin A activated human T cells. J Immunol 1990; 144: 4663-4669.

9. Fleischer B, Schrezenmeier H, Conradt P. T lymphocyte activation by staphylococcal enterotoxins: role of class II molecules and T cell surface structures. Cell Immunol 1989, 120: $92-101$.

10. Jupin C, Anderson S, Damais C, Alouf JE, Parant M. Toxic shock syndrome toxin 1 as an inducer of human tumor necrosis factors and $\gamma$ interferon. $J \operatorname{Exp} M e d$ 1988; 167: 752761

11. Parsonnet J, Hickman RK, Eardley DD, Pier GB. Induction of human interleukin-1 by toxic-shock-syndrome toxin-1. J Infect Dis 1985; 151: 514-522.

12. Johnson HM, Russell JK, Pontzer CH. Staphylococcal enterotoxin microbial superantigens. FASEB $J$ 1991; 5: 27062712.

13. Kappler J, Kotzin B, Herron L et al. V $\beta$-specific stimulation of human T cells by staphylococcal toxins. Science 1989; 244 811-813.

14. Marrack P, Kappler J. The staphylococcal enterotoxins and their relatives. Science 1990; 248: 705-711.

15. Mollick JA, Cook RG, Rich RR. Class II MHC molecules are specific receptors for Staphylococcus enterotoxin A. Science 1989; 244: 817-820.
16. Uchiyama $T$, Imanishi $K$, Saito $S$ et al. Activation of human $T$ cells by toxic shock syndrome toxin-1: the toxin-binding structures expressed on human lymphoid cells acting as accessory cells are HLA class II molecules. Eur $J$ Immunol 1989; 19: 1803-1809.

17. Naidu AS, Voros S, Loczi G, Kienle Z, Brasch B, Emody L Toxic shock syndrome toxin-1 (TSST-1) production in staphylococcal infections and serological implications with patients and healthy controls. Acta Microbiol Hung 1989; 36: 19-24.

18. Vischer WA, Stalder H, Faupel DM. Frequency of toxic-shocksyndrome-toxin producing strains of Staphylococcus aureus in the Basel region. Schweiz Med Wochenschr 1985; 115: 1196 1199.

19. Pozhar PF, Akatov AK, Ratgauz GL, Fluer FS, Atopek S. Ia. The frequency of the production of toxic-shock exotoxin by Staphylococcus aureus strains isolated in the USSR (In Russian). Zh Mikrobiol Epidemiol Immunobiol 1989; (8) 3-5.

20. von Reyn CF, Levy BS, Arbeit RD, Friedland G, Crumpacker CS. Infective endocarditis: an analysis based on strict case definitions. Ann Intern Med 1981; 94: 505-518.

21. Humphreys H, Keane CT, Hone $\mathrm{R}$ et al. Enterotoxin production by Staphylococcus aureus isolates from cases of septicaemia and from healthy carriers. $J$ Med Microbiol 1989 ; 28: $163-172$.

22. Kunstmann G, Schröder E, Hasbach H, Pulverer G. Immune response to toxic-shock-syndrome toxin-1 (TSST-1) and to staphylococcal enterotoxins A, B and C in Staphylococcus aureus infections. Int $J$ Med Microbiol 1989; 271: 486-492.

23. Christensson B, Hedström SÅ. Biochemical and biological properties of Staphylococcus aureus septicaemia strains in relation to clinical characteristics. Scand J Infect Dis 1986; 18 297-303.

24. Moseley AB, Huston DP. Mechanism of Staphylococcus aureus exotoxin A inhibition of Ig production by human B cells J Immunol 1991; 146: 826-832.

25. Edwin C, Tatini SR. Maheswaran SK. Specificity and crossreactivity of staphylococcal enterotoxin A monoclonal antibodies with enterotoxins B, C1, D, and E. Appl Environ Microbiol 1986; 52: 1253-1257.

26. Thompson NE, Ketterhagen MJ, Bergdoll MS. Monoclonal antibodies to staphylococcal enterotoxins $B$ and $C$ : crossreactivity and localization of epitopes on tryptic fragments. Infect Immun 1984; 45: 281-285. 